\title{
Surface and Tower Meteorological Instrumentation at NSA Handbook
}

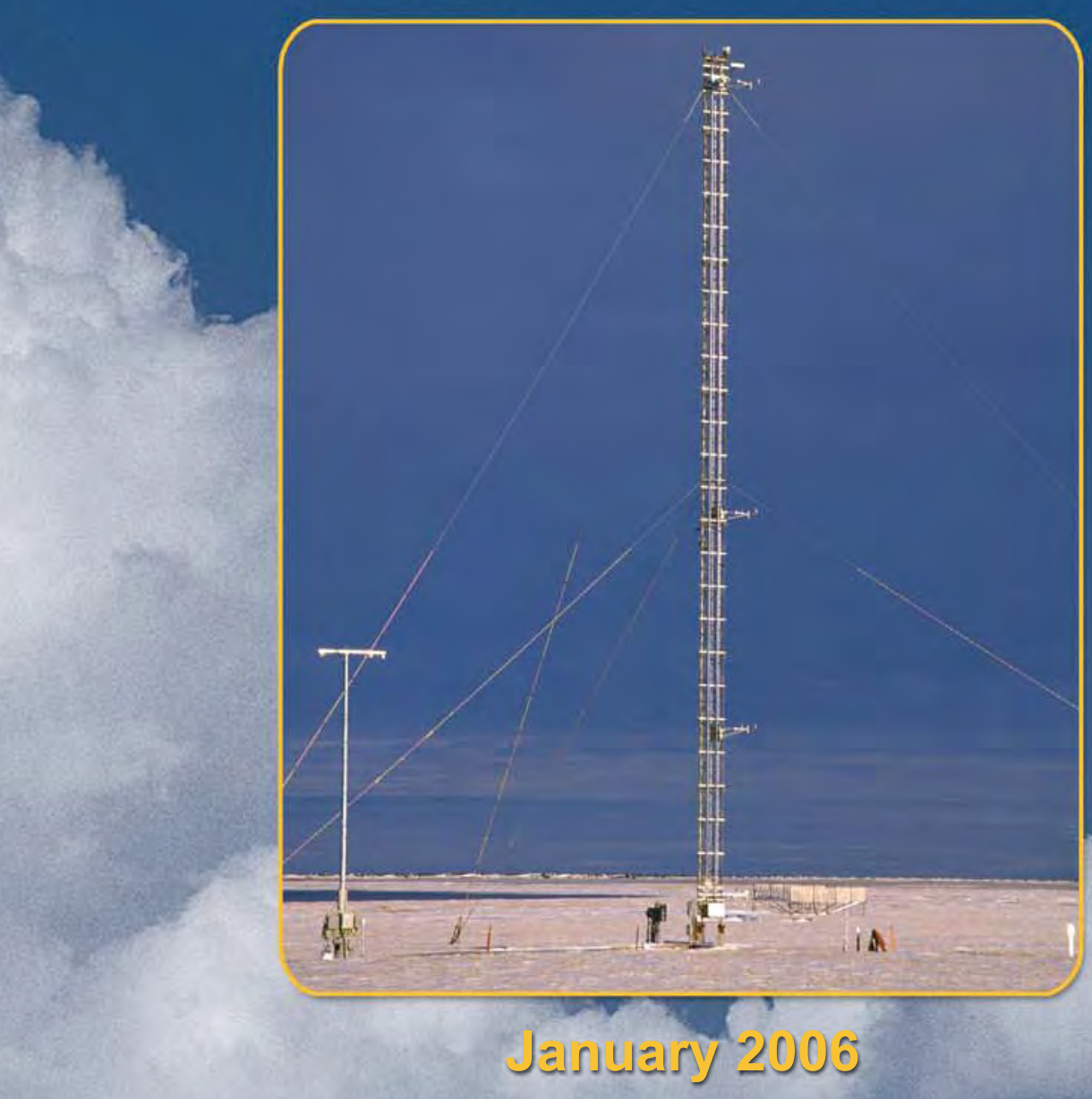

Work supported by the U.S. Department of Energy Office of Science, Office of Bjological and Environmental Research 


\section{Surface and Tower Meteorological Instrumentation at NSA}

January 2006

M.T. Ritsche

Work supported by the U.S. Department of Energy, Office of Science, Office of Biological and Environmental Research 


\section{Contents}

1. Surface and Tower Meteorological Instrumentation at Atqasuk (METTWR2H)............................ 1

2. Surface and Tower Meteorological Instrumentation at Barrow (METTWR4H) .............................. 1

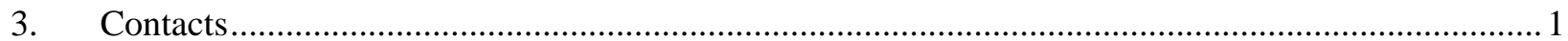




\section{Surface and Tower Meteorological Instrumentation at Atqasuk (METTWR2H)}

\subsection{General Overview}

The Surface and Tower Meteorological Instrumentation at Atqasuk (METTWR2H) uses mainly conventional in situ sensors to measure wind speed, wind direction, air temperature, dew point and humidity mounted on a 10-m tower. It also obtains barometric pressure, visibility, and precipitation data from sensors at or near the base of the tower. In addition, a Chilled Mirror Hygrometer is located at $1 \mathrm{~m}$ for comparison purposes. Temperature and relative humidity probes are mounted at $2 \mathrm{~m}$ and $5 \mathrm{~m}$ on the tower. For more information, see the Surface and Tower Meteorological Instrumentation at Atqasuk Handbook.

The original configuration and collection system for the METTWR2H was installed in July 2000. In October 2003, the configuration and collection system was changed considerably. Information on the data, sensors, and measurement methods prior to October 2003 can be found in the Atqasuk Meteorology Station (AMET) Handbook.

\section{Surface and Tower Meteorological Instrumentation at Barrow (METTWR4H)}

\subsection{General Overview}

The Surface and Tower Meteorological Instrumentation at Barrow (METTWR4H) uses mainly conventional in situ sensors mounted at four different heights (2 m, 10 m, $20 \mathrm{~m}$ and $40 \mathrm{~m}$ ) on a 40-m tower to obtain profiles of wind speed, wind direction, air temperature, dew point and humidity. It also obtains barometric pressure, visibility, and precipitation data from sensors at the base of the tower. In addition, a Chilled Mirror Hygrometer and an ultrasonic wind speed sensor are located near the $2 \mathrm{~m}$ level for comparison purposes. For more information, see the Surface and Tower Meteorological Instrumentation at Barrow Handbook.

The original configuration and collection system for the METTWR4H was installed in March 1998. In October 2003, the configuration and collection system was changed considerably. Information on the data, sensors, and measurement methods prior to October 2003 can be found in the Barrow Meteorology Station (BMET) Handbook.

\section{Contacts}

\subsection{Mentor}

Michael Ritsche, Scientific Associate

Argonne National Laboratory

9700 South Cass Avenue, Bldg. 203

Argonne, IL 60439

Phone: 630-252-1554

Fax: 630-252-5498

Email: mtritsche@anl.gov 